\title{
1 Survival of the Systems
}

2 Timothy M. Lenton ${ }^{1, *}$, Timothy A. Kohler ${ }^{2,3,4}$, Pablo A. Marquet ${ }^{3,5,6}$, Richard A. Boyle ${ }^{1}$,

3 Michel Crucifix ${ }^{7}$, David M. Wilkinson ${ }^{8,9}$, Marten Scheffer ${ }^{10}$

$4{ }^{1}$ Global Systems Institute, University of Exeter, EX4 4QE, UK

$5 \quad{ }^{2}$ Department of Anthropology, Washington State University, Pullman, WA 99164-4910, USA

$6 \quad$ SSanta Fe Institute, Santa Fe, NM 87501, USA

$7 \quad{ }^{4}$ Crow Canyon Archaeological Center, Cortez, CO 81321

$8 \quad{ }^{5}$ Departamento de Ecología, Facultad de Ciencias Biológicas, Pontificia Universidad Católica

9 de Chile, Alameda 340, Santiago, Chile

$10{ }^{6}$ Instituto de Ecología y Biodiversidad (IEB), Centro de Cambio Global UC, Laboratorio

11 Internacional de Cambio Global (LINCGlobal)

127 Université catholique de Louvain, Earth and Life Institute, Louvain-la-Neuve, Belgium

${ }^{8}$ School of Life Sciences, University of Lincoln, LN6 7DL, UK

${ }^{9}$ Classics and Archaeology, University of Nottingham, NG7 2RD, UK

${ }^{10}$ Aquatic Ecology and Water Quality Management, Wageningen University, 6700AA

Wageningen, The Netherlands

*Corresponding author: Lenton, T. M. (t.m.lenton@exeter.ac.uk)

18 Keywords

19 Selection | persistence | feedback cycle | ecosystem | social-ecological system 


\section{Abstract}

Since Darwin, individuals and more recently genes have been the focus of evolutionary thinking. The idea that selection operates on non-reproducing, higher-level systems including ecosystems or societies has met with scepticism. But research emphasising that natural selection can be based solely on differential persistence invites reconsideration of their evolution. Self-perpetuating feedback cycles involving biotic as well as abiotic components are critical to determining persistence. Evolution of autocatalytic networks of molecules is well studied, but the principles hold for any 'self-perpetuating' system. Ecosystem examples include coral reefs, rainforests and savannahs. Societal examples include agricultural systems, dominant belief systems and economies. Persistence-based selection of feedbacks can help us understand how ecological and societal systems survive or fail in a changing world.

\section{Evolution based on persistence}

In times of pervasive global change it is important to ask: Why do some ecological, social or social-ecological systems dominate the world today? Why not others? Plausibly the winners we see have out-persisted other systems. But how does that work? And can we view it as an evolutionary process?

The founders of ecology and biogeochemistry thought so. Tansley [1] argued that there is "a kind of natural selection of incipient systems, and those which can attain the most stable equilibrium survive the longest". Hutchinson [2] postulated that systems with self-correcting mechanisms tend to persist longer, and disruptive elements tend to get filtered out by causing their own extinction. Subsequent researchers argued "the criterion for selection is 
survival of the system" [3] and that ecosystems have become more stable over time through undergoing a winnowing series of "limited catastrophes" [4]. Archaeologists and anthropologists advanced comparable ideas involving differential persistence of cultural groups $[5,6]$, with state formation occurring through a sequence of "experiments", which often fail but sometimes achieve a persistent configuration [7].

Evolutionary theory, however, has struggled to accommodate such explanations. It generally refuses to recognise ecosystem evolution (see Glossary) $[3,4,8]$, because that involves systems of unrelated species that do not faithfully replicate as a whole - despite having some limited heritability [9]. Whilst cultural evolution is widely recognised [5, 10-13], and often involves only distantly related humans, most theory focuses on lower levels of selection than whole societies or cultures - because the latter do not faithfully replicate as a whole. But if both social systems and ecosystems have irreducible properties at the systemlevel, then (how) can those properties evolve?

Recent theory [14-21] highlights that natural selection does not require replication and instead can be based on variation in persistence alone. The basic idea of persistence-based selection is straightforward: Some systems tend to spread through space at the expense of others and persist longer over time than others, and thus come to dominate the world. Persistence in turns increases the chances of acquiring further persistence-enhancing traits - providing a potential mechanism of adaptation [17]. Variation could be amongst a population of non-interacting, non-reproducing systems, e.g. a hypothetical population of planetary-scale biospheres $[17,19,21]$, or amongst interacting populations of nonreproducing systems $[18,20,21]$ - re-opening the tantalising possibility of whole social and/or ecological system evolution. 
65

66

67

\section{Feedback cycles as units of persistence-based selection}

Building on recent $[18,19,22,23]$ and earlier $[2,24]$ work, we argue that biotic feedback cycles - closed loops of causal interactions involving life - are key units of persistence-based selection. Box 1 and Table 1 relate this to existing theory.

Feedback loops have irreducible properties that cannot be exhibited by any of their individual components in isolation [24] - including the overall sign and strength ('gain') of the feedback. Abiotic systems subject to an external supply of free-energy develop structures - such as waves, galaxy spiral arms, convection cells, or snow crystals - which rely on unstable modes of motion which grow exponentially because of self-amplifying (positive) feedbacks [25]. A stationary state emerges when the free energy dissipated around these structures balances the external supply.

This provides a starting point to think about the development of complex ecological and social systems. Hypercycles [26] and other autocatalytic networks of molecules [27], are widely recognised as irreducible self-amplifying phenomena [28] integral to the origin of life. Autocatalytic networks can grow in complexity, as well as size, by acquiring more selfperpetuating feedback cycles [29].

However, biological systems - in contrast to abiotic ones - have the capacity to transfer context-dependent information through time or space by mechanisms including heritability and signalling, which generally involve information-carrying molecules. These uniquely biological traits provide the foundation for evolution by learning and adaptation [24, 30], including replication-based selection. 
Feedback cycles in ecosystems [31] and social systems generally involve multiple, genetically-unrelated components, either fulfilling different functions within a cycle, or representing diversity amongst the performers of a given function. We argue that their irreducible, higher-level properties may be subject to selection based purely on differential spread and persistence - with these measures of relative system performance providing an analogue to conventional 'fitness' (Table 1). There are several proposed mechanisms through which such persistence-based selection could occur (Table 1) (see 'Finding stability'). When combined with lower-level replication-based selection the result may be a form of type '2' multi-level selection [28] (Box 1, Table 1).

We define the corresponding (ecological or social) system as comprised of multiple feedback cycles that contribute to its identity (i.e. what is maintained through time and space for it to be considered the same system) [32]. A system's spatial boundaries may be set by physical constraints (e.g. island area) or by the extent of spatial influence of its components, their relationships, and resultant feedbacks, bounding against other systems. We define creation as when a new system identity arises, and destruction (or collapse) as when identity is lost [32]. Persistence (lifetime) can be measured as the intervening interval. Box 1 addresses the critical issue of how feedback information is transmitted through time.

For ongoing selection to occur (at the system-level) there must be a source of variation: Evolution at lower levels can give rise to changes in information at the system level [28], particularly when a new interaction or variant of an existing interaction gives rise to a new feedback cycle or a new variant of an existing feedback. Box 2 considers inter-system dispersal as a further source of variation. 
Feedback cycles can be built from the by-products of traits that are naturally selected at lower (e.g. individual, gene) levels [33]. This reduces the problem of invoking altruism to close feedback cycles - as in that case, natural selection can favour components that disrupt or break the cycles. It differentiates this review from extensive work on the evolution of altruism by multi-level selection [28].

Feedback cycles can be continually regenerated by different organisms performing the same metabolic function with the same by-products, e.g. members of a microbial guild [18]. This provides continuity of information over time (Box 1) in the same gene complexes encoding particular metabolisms, regardless of the organisms carrying them [34] - as well as in the persistence of the feedback cycle structure [35] - adding for societies behavioural or symbolic inheritance systems [36].

\section{Types of self-perpetuating feedback}

Several key types of self-perpetuating feedback can form a basis for persistence-based selection.

\section{Resource acquisition and recycling}

Resource recycling (Fig. 1a,b) is self-perpetuating in that it decouples productivity and population size from being wholly limited by external supply fluxes of material resources, which may be meagre [21]. This benefits all members of a recycling loop. Recycling is irreducible in that it requires multiple, different, usually unrelated components, in both ecosystems and social-ecological systems.

Resource-recycling microbial ecosystems built on 'waste' by-products robustly emerge in evolutionary simulations [23, 35, 37-39], and in experiments [40], and can evolve into 
altruistic recycling [41]. Nutrient cycle assembly can be helped by 'waste' consumption by one microbial guild enhancing its production by another, which increases the resulting free energy yield [42]. In plant-decomposer models, natural selection for improved individual resource competition can increase system-level cycling over time [43]. Even if there is an evolutionary cost to closing a recycling loop (altruism), this can be overcome by positive fitness feedbacks within cellular clusters [41], or by recycling systems spreading at the expense of non-recycling ones, because they support denser populations [38] (Box 2). Realworld examples of recycling therefore abound. The Amazon rainforest maintains stunning productivity through highly effective nutrient recycling on otherwise very nutrient-poor highly weathered soils [44] and by recycling its own rainfall [45]. Global recycling ratios of essential elements range from $\sim 10$ for sulphur to $>1000$ for phosphorus [46].

An input of free energy is required to power a recycling loop (Fig. 1a), which usually comes from autotrophic members of the loop (e.g. plants). Some members may also enhance the input of the material resource(s) being recycled. For example, nitrogen fixers produce a costly, leaky public good - available nitrogen - enjoyed by other members of the ecosystem. Hence as nitrogen fixers become more common and increase available nitrogen levels, negative feedback regulates their abundance [47]. Nitrogen fixation in turn fuels a nitrogen cycle which contains diverse components and is a candidate unit of persistence-based selection $[18,19]$.

Other resource-acquisition strategies have a more favourable cost-benefit for the acquirers. In coral reef ecosystems, sponges filter-feed on coral mucous and dissolved organic matter from the water column and convert it to particulate organic matter, also shedding their cells, providing a resource for other ecosystem members. The resulting sponge loop is an 
integral part of the self-perpetuating recycling coral reef system that involves many unrelated functional groups and helps support a large population of sponges [48]. Other resource-acquisition and recycling strategies have evolved into tight symbioses. Some involve multiple, unrelated resource acquirers, making conventional evolutionary explanations problematic - for example, both cyanobacteria and eukaryotic algae in symbiosis with a fungus within one lichen [49].

Over geologic time, more productive resource acquisition and recycling systems have displaced less productive ones [50]. In the progressive colonisation of the land, microbial mats, lichens and non-vascular plants, have largely been displaced by vascular plantdominated ecosystems that are more effective at acquiring and recycling nutrients [51]. Larger plants also transpire more, supporting more rainfall and hence larger plants [52]. Subsequently, angiosperm ecosystems with a resource-recycling plant-fungal relationship, have displaced gymnosperm ecosystems with a resource-acquisition plant-fungal relationship, in many areas [53].

Human agricultural systems, with 6-10 independent regional origins during the Holocene, represent hugely successful resource acquisition and recycling systems (Fig. 1b), which have spread across the world and persisted for thousands of years, accumulating countless improvements. They capture solar energy and via human and animal labour transform it into consumable calories more efficiently than previous systems dependent on wild plants. The domesticators were consequently also domesticated. More settled households could better monitor plant growth and protect plants from predation by other animals or other people. They also accumulated waste which could be recycled to infields at very low cost with high rewards to plant productivity. Where readily domesticated animals were available, 
recycling of animal manure added to a highly productive, self-perpetuating system [54]. The addition of charcoal and other organic matter to Amazonian soils, creating 'terra preta' and other 'anthropogenic dark earths' [55], helped the recycling of water and nutrients and plausibly boosted the success of communities using this technology [56]. Efficient water use and recycling through diverse capture, storage and irrigation systems has also been integral to the persistence of many ancient and modern societies [57].

In early agrarian societies, resource extraction began with the use of natural islands of fertility. Landesque capital [58] captures the idea that by investing in productivity-improving technologies (e.g. pre-Colombian use of guano as fertiliser, terracing) the population a landscape can support increases, in a self-perpetuating cycle. Whilst this can be interpreted as due to a family's or a society's investment in its own success, the exceedingly long duration of soil enrichments by mobile herders in African savannahs [59], provide an example of ecological legacy that is broadly dispersed to many organisms and societies. The system of pastoralism may even have locally delayed the demise of the "Green Sahara" well beyond what would be predicted from orbital-driven climate change [60]. Conversely, where land-use change degrades the environment, self-perpetuating feedbacks working in the opposite direction can bring about the collapse of social-ecological systems - for example in the Dust Bowl across the American Great Plains during the 1930s [61, 62].

\section{Local environmental alteration}

Material resources are not always the limiting factor for system productivity and spread.

Sometimes environmental conditions such as temperature or $\mathrm{pH}$ are limiting and feedbacks alter these conditions in a manner that is self-perpetuating. In principle, such environmental alteration might derive from a single species, but in practice examples of successful artificial 
ecosystem selection for environmental properties $[63,64]$ appear to involve multiple species $[64,65]$ affecting the same environmental variable to differing degrees and sometimes in opposing directions.

Evolutionary simulations show that microbial ecosystems whose diverse metabolic byproducts collectively improve aspects of their environment which are limiting to the growth of their constituents, have denser populations than ecosystems that degrade their environment [66]. Hence under conditions of selectively neutral genetic dispersal (Box 2) environment-improving ecosystems tend to spread and persist at the expense of environment-degrading ones [66]. Diverse real-world ecosystem engineers [67] often alter their environment in a manner that enhances their persistence. For example, different Sphagnum moss species contribute to acidifying and waterlogging the soil, thus perpetuating the peat bog ecosystem by preventing trees from establishing [68]. Forests of diverse tree species, in contrast, typically modify their micro-climate in a manner that enhances tree growth [69]. Reintroducing ecosystem engineers and promoting such positive feedbacks can be key to successful ecosystem restoration [70].

Humans also often improve their local environments in self-perpetuating ways. This started with fire as a technology that warms up humans in cold conditions, detoxifies food, improves caloric intake, and provides protection from predators [71]. Later the construction of buildings created a regulated micro-environment for humans (and often their domesticated livestock), which both persisted across generations and enhanced the persistence of their inhabitants. 


\section{Disturbance enhancement}

Feedback between the biological members of a system and a disturbance factor that benefits that system over others can be self-perpetuating (Fig. 1c).

Grasslands promote fire and herbivory, in self-perpetuating feedbacks that displace forests.

This has enabled grasslands to cover a third of the Earth's productive land surface in just the last $\sim 35$ million years. Anti-flammability is a more plausible individual-level adaptation hence promoting flammability is argued to be a systems-level property [72]. Transplant experiments have shown that fire, rather than climate, limits the distribution of trees in the African savannah [73]. Together, fire and herbivores tend to remove trees and suppress their regeneration - forming a potentially lethal combination for woody plants [74].

Early human social groups using fire in hunting facilitated the transition of forest to grassland and savannah. This may have positively fed back on the hunters by supporting a greater food source. In Australia, small-scale Aboriginal hunting fires buffered the landscape against large-scale fires started by lightning strikes, thus maintaining greater mammal diversity [75]. The later domestication of livestock was also self-perpetuating; domesticated herbivores got rid of trees, thus tending to maintain a pasture state in which they thrived.

The introduction of fire and domesticated herbivores to New Zealand illustrates selfperpetuation of the pasture state [76].

In cultural evolution, grasslands inhabited by horse-riding nomads are seen as a source region for military technological innovation and warfare [10] - where war is an extreme disturbance factor for societies. The resulting conflicts are argued to have selected for altruistic ultra-social traits (particularly self-sacrifice as part of an army), and through the assimilation of cultural traits of the victors, to the emergence of increased agrarian state 
complexity. If this complexity - resulting in resources that could be plundered - in turn led to more aggressive, war-waging behaviour, then a self-perpetuating feedback loop would be closed. Agrarian societies, by supporting a transition to grasslands and domesticating horses, may have closed a further feedback loop. For example, European settlers introduced horses to Native American communities, who then rapidly assimilated them into trade networks, hunting practices, and resistance against the invaders (e.g. the Comanche). The independent origin of this feedback, recognised in earlier Eurasian contexts [10], supports it being a potential unit of persistence-based selection.

\section{Feedbacks involving diversification and specialisation}

Self-perpetuating systems typically support diversification and specialisation within them, producing further feedback [35, 39] (Fig. 2). This is abundantly clear in societies. Productive systems based on plant and animal domestication may produce surpluses which can be concentrated in a small social segment which in turn may sponsor specialists to provide this elite with socially valuable goods. In places where cattle were domesticated, oxen could be used to extend farming well beyond the infields, providing new sources of revenue for their owners [77]. Resulting feedbacks may, ultimately, help explain the typically greater wealth concentration, technological innovation, and specialization in late prehistoric Eurasian societies than among late prehispanic societies in the Americas [78].

The intensification of labour in agriculture was incentivised at the household level and increased production at the social system level. Investment of labour into the landscape and taxation in turn provided ways of gathering and privatizing common pool resources. This began to subsume agroecosystems within larger food systems and economic systems. Further diversification and specialisation is seen in more productive social systems [79], 
where cycling can take new material and non-material forms - classically described by

Durkheim as the shift from mechanical solidarity to organic solidarity [80].

In ecology, the most intensive resource-recycling systems, including coral reefs and the Amazon rainforest, are also the most spectacularly biodiverse, plausibly because effective recycling both requires a diversity of functional roles and supports increased diversity within those roles. The resulting functional redundancy [18], gives ecosystems robustness against extinctions and resilience to perturbations. Increased species diversity can increase net primary production and reduce the risk of exotic species invasion, thanks to inter-species niche complementarity and facilitative interactions that increase resource extraction and use, and make them available to the rest of the community via recycling $[81,82]$.

\section{Finding stability}

What constrains the spread of self-amplifying (positive) feedbacks and gives rise to stability? Individual feedbacks can be bounded by their own limited strength, by other constraints kicking in, or in biological systems by driving themselves past optimal conditions for their perpetrators and into a regime of self-stabilising (negative) feedback. More complex systems can find stable configurations through trial-and-error 'experiments' [1-4, 7]. Ashby [83] first demonstrated an abiotic mechanism for such sequential selection [21], whereby a system that left prescribed tolerable bounds randomly rewired its connections, repeatedly, until a stable configuration was found within tolerable bounds, which by definition tended to persist. Collapse and random rewiring destroy memory and hence the potential for evolution. However, in biological systems more incremental reconfiguration can find stability whilst retaining information through time (e.g. in the gene pool or in written records). Whilst sequential selection applies to repeated trials of one system over time, 
stability-based sorting $[22,84]$ considers populations of interacting systems that differ in their stability properties - with the most stable coming to predominate.

291

In ecology, selection based on stability is recognised across a range of scales $[21,84]$.

Selective extinction at the species level has long been recognised [85]. In the construction of food webs [86], the steady arrival of species at a given location - thanks to natural selection favouring dispersal [87] - can add to an incumbent community or destabilise it, driving other species to extinction - but once a stable configuration is found it (by definition) persists. Recent models extend this to show how life-environment coupled systems can find stable configurations [21]. Fossil data shows stable ecological configurations prior to the End Permian mass extinction, 'random rewiring' in the aftermath, then the emergence of new stable ecological configurations [88].

Sequential selection of stable social systems is seen in the history of state formation in Madagascar, Mesopotamia and the US Southeast [7]. In the northern Pueblo region of the US Southwest there were at least four successive attempts to achieve stable socio-political formations, each ending in pulses of violence, marked declines in wealth inequality, and local and regional disaggregation $[89,90]$. Each time high proportions of the population and their cultural repertoire survived. Finally, around AD 1300 relatively stable socio-political formations emerged, only to be disrupted two centuries later by the invading Spanish. Similar patterns are visible in the persistence of foraging systems across the ice age to Holocene transition in the Levant [91], and in early Holocene farming societies of southwest Central Europe [92]. They may be especially prominent among societies developing novel forms of subsistence and social organization. 
Social systems contain endogenously generated practices and institutions, such as law enforcement, democracy and organised religions that promote internal stability and persistence. Whilst some are portrayed as deliberately constructed stabilising mechanisms [93], others were presumably chanced upon, but then enhanced their own persistence. Ritual can play a key role in social-ecological system regulation. For example, the ritual sacrifice of pigs among the Maring tribe of Papua New Guinea helps restore a sustainable ratio of pigs to humans, provides food, and prevents land degradation [94].

The endogenous generation of new feedbacks (e.g. by random mutation or cultural innovation) and subsequent sequential selection of persistence-enhancing ones, provides a plausible mechanism to accumulate system-level complexity, as well as stability [17-19]. However, it is too slow to account for rapid, recent cultural evolution [12] - plausibly because it lacks a mechanism for recombination of beneficial innovations occurring in different systems (Box 2).

\section{Concluding remarks}

A 'survival of the systems' perspective can help us understand the changing predominance of ecological, social and social-ecological systems, including those driving and responding to contemporary global change.

The ideas discussed need to be formalised and tested (see Outstanding Questions). Existing theories of feedbacks and multi-level selection could be combined. Resulting theory could be tested in the lab by sequentially assembling microbial microcosms from sequenced representatives of functional guilds, and e.g. examining the relative persistence of nonrecycling and recycling systems in isolation [95], then allowing them to interact through 
limited mixing to see which predominates. If persistence-based selection supports systemscale evolution, then cases of convergent system evolution would be expected. For example, savannah ecosystems found in South America, Africa, India and Australia all have a similar functional structure even though the species involved differ [74]. Statistical patterns in ancient and contemporary ecosystems could also provide a test of the persistence of particular ecosystem configurations - noting the remarkable similarity of reconstructed Cambrian food webs and present ones [96]. Differential persistence as a mechanism of replacing cultural norms with more persistent ones, already has empirical support in that its timescale fits early cultural evolution [6]. System-level persistence-based selection may also explain the existence of archaeological cultures (or "traditions") - for example, Pueblo societies comprised of several ethnolinguistic groups [97]. Such cultures link disparate populations, built on exchanges of people, goods, and ways of life that provide mechanisms for recombination and accumulation of technologies and practices.

The industrial revolution was propelled by self-perpetuating feedbacks between new technologies, capitalism and an expanding labour force [98]. It continues to spread around the world, as banks finance and governments subsidise resource-extraction industries, which repay them with capital and contented voters. For some, the technosphere has coopted humans to perpetuate itself [99]. But powering it with fossil fuel burning cannot persist - the resource is finite and the externalities are cumulatively toxic [100]. If achieving long-term sustainability requires fundamental changes, ranging from sustainable energy and increased material recycling to different governance structures [101], these can be viewed as alternative systems to the currently predominant one. The salient questions then become: Under what conditions can such alternative systems spread at the expense of the 
incumbent one(s)? Must the currently predominant system fail (to persist) before another can replace it? Or can we find ways to promote collective human persistence without going through such a crude and potentially brutal selection mechanism?

\section{Acknowledgements}

We thank the four reviewers and Santa Fe Institute working group participants Andrew Gillreath-Brown, Jennifer Dunne, Henry Wright and Chi Xu for valuable input.

\section{References}

1. Tansley, A.G. (1935) The Use and Abuse of Vegetational Concepts and Terms. Ecology 16, 284-307

2. Hutchinson, G.E. (1948) Circular causal systems in ecology. Annals of the New York Academy of Sciences 50, 221-246

3. Dunbar, M.J. (1960) The Evolution of Stability in Marine Environments Natural Selection at the Level of the Ecosystem. The American Naturalist 94, 129-136

4. Ott, J.A. (1981) Adaptive Strategies at the Ecosystem Level: Examples from Two Benthic Marine Systems. Marine Ecology 2, 113-158

5. Boyd, R., and Richerson, P.J. (1990) Group selection among alternative evolutionarily stable strategies. Journal of Theoretical Biology 145, 331-342

6. Soltis, J., et al. (1995) Can Group-Functional Behaviors Evolve by Cultural Group Selection?: An Empirical Test. Current Anthropology 36, 473-494

7. Wright, H.T. (2006) Early State Dynamics as Political Experiment. Journal of Anthropological Research 62, 305-319 
$3778 . \quad$ Ibanez, S. (2020) The Evolution of Ecosystem Phenotypes. Biological Theory 15, 91-

$378 \quad 106$

379 9. Goodnight, C.J. (2000) Heritability at the ecosystem level. Proceedings of the $380 \quad$ National Academy of Sciences 97, 9365-9366

381 10. Turchin, P., et al. (2013) War, space, and the evolution of Old World complex 382 societies. Proceedings of the National Academy of Sciences 110, 16384-16389

383 11. Richerson, P., et al. (2014) Cultural group selection plays an essential role in 384 explaining human cooperation: A sketch of the evidence. Behavioral and Brain Sciences 39, 385 e30

12. Boyd, R., and Richerson, P.J. (2002) Group Beneficial Norms Can Spread Rapidly in a Structured Population. Journal of Theoretical Biology 215, 287-296

13. Boyd, R., and Richerson, P.J. (2009) Voting with your feet: Payoff biased migration and the evolution of group beneficial behavior. Journal of Theoretical Biology 257, 331-339

14. Dussault, A.C., and Bouchard, F. (2017) A persistence enhancing propensity account of ecological function to explain ecosystem evolution. Synthese 194, 1115-1145

15. Bouchard, F. (2014) Ecosystem Evolution is About Variation and Persistence, not Populations and Reproduction. Biological Theory 9, 382-391

16. Bourrat, P. (2014) From survivors to replicators: evolution by natural selection revisited. Biology \& Philosophy 29, 517-538

17. Doolittle, W.F. (2014) Natural selection through survival alone, and the possibility of

18. Doolittle, W.F., and Inkpen, S.A. (2018) Processes and patterns of interaction as units of selection: An introduction to ITSNTS thinking. Proceedings of the National Academy of 
401

402

403

404

405

406

407

408

409

410

411

412

413

414

415

416

417

418

419

420

421

422

423

424

19. Doolittle, W.F. (2017) Darwinizing Gaia. Journal of Theoretical Biology 434, 11-19

20. Doolittle, W.F. (2019) Making Evolutionary Sense of Gaia. Trends in Ecology \&

Evolution 34, 889-894

21. Lenton, T.M., et al. (2018) Selection for Gaia across multiple scales. Trends in Ecology \& Evolution 33, 633-645

22. Toman, J., and Flegr, J. (2017) Stability-based sorting: The forgotten process behind (not only) biological evolution. Journal of Theoretical Biology 435, 29-41

23. Liu, Y., and Sumpter, D. (2017) Insights into resource consumption, cross-feeding, system collapse, stability and biodiversity from an artificial ecosystem. Journal of The Royal Society Interface 14, 20160816

24. Ulanowicz, R.E. (1990) Aristotelean Causalities in Ecosystem Development. Oikos 57, $42-48$

25. Drazin, P.G., and Reid, W.H. (2004) Hydrodynamic Stability. Cambridge University Press

26. Eigen, M. (1971) Selforganization of matter and the evolution of biological macromolecules. Naturwissenschaften $58,465-523$

27. Kauffman, S.A. (1986) Autocatalytic sets of proteins. Journal of Theoretical Biology $119,1-24$

28. Okasha, S. (2006) Evolution and the Levels of Selection. Oxford University Press

29. Jain, S., and Krishna, S. (2001) A model for the emergence of cooperation, interdependence, and structure in evolving networks. Proceedings of the National Academy of Sciences 98, 543-547

30. Watson, R.A., and Szathmáry, E. (2016) How Can Evolution Learn? Trends in Ecology \& Evolution 31, 147-157 
31. Cazzolla Gatti, R., et al. (2018) Niche emergence as an autocatalytic process in the evolution of ecosystems. Journal of Theoretical Biology 454, 110-117

32. Cumming, G.S., and Peterson, G.D. (2017) Unifying Research on Social-Ecological Resilience and Collapse. Trends in Ecology \& Evolution 32, 695-713

33. Lenton, T.M. (1998) Gaia and natural selection. Nature 394, 439-447

34. Gardner, A. (2015) The genetical theory of multilevel selection. Journal of

Evolutionary Biology 28, 305-319

35. Crombach, A., and Hogeweg, P. (2009) Evolution of resource cycling in ecosystems and individuals. BMC Evolutionary Biology 9, 122

36. Jablonka, E., and Lamb, M.J. (2005) Evolution in Four Dimensions: Genetic, Epigenetic, Behavioral, and Symbolic Variation in the History of Life. MIT press

37. Williams, H.T.P., and Lenton, T.M. (2007) The Flask model: Emergence of nutrientrecycling microbial ecosystems and their disruption by environment-altering 'rebel' organisms. Oikos 116, 1087-1105

38. Boyle, R.A., et al. (2012) Natural selection for costly nutrient recycling in simulated microbial metacommunities. Journal of Theoretical Biology 312, 1-12

39. Germerodt, S., et al. (2016) Pervasive Selection for Cooperative Cross-Feeding in Bacterial Communities. PLOS Computational Biology 12, e1004986

40. Harcombe, W. (2010) Novel cooperation experimentally evolved between species. Evolution 64, 2166-2172

41. Preussger, D., et al. (2020) Reciprocal Fitness Feedbacks Promote the Evolution of Mutualistic Cooperation. Current Biology, in press

42. Seto, M., and Iwasa, Y. (2019) The fitness of chemotrophs increases when their catabolic by-products are consumed by other species. Ecology Letters 22, 1994-2005 
43. Loreau, M. (1998) Ecosystem development explained by competition within and between material cycles. Proceedings of the Royal Society of London. Series B: Biological Sciences $265,33-38$

44. Vitousek, P.M., and Sanford, R.L. (1986) Nutrient Cycling in Moist Tropical Forest. Annual Review of Ecology and Systematics 17, 137-167

45. Eltahir, E.A.B., and Bras, R.L. (1994) Precipitation recycling in the Amazon basin.

Quarterly Journal of the Royal Meteorological Society 120, 861-880

46. Lenton, T.M., et al. (2020) Life on Earth is hard to spot. The Anthropocene Review 7, $248-272$

47. Morris, J.J., et al. (2012) The Black Queen Hypothesis: Evolution of Dependencies through Adaptive Gene Loss. mBio 3, e00036-00012

48. de Goeij, J.M., et al. (2013) Surviving in a Marine Desert: The Sponge Loop Retains Resources Within Coral Reefs. Science 342, 108-110

49. Henskens, F.L., et al. (2012) Cyanolichens can have both cyanobacteria and green algae in a common layer as major contributors to photosynthesis. Annals of Botany 110, $555-563$

50. Lenton, T.M., and Watson, A.J. (2011) Revolutions that made the Earth. Oxford University Press

51. Porada, P., et al. (2014) Estimating impacts of lichens and bryophytes on global biogeochemical cycles. Global Biogeochemical Cycles, DOI: 10.1002/2013GB004705 52. Berry, J.A., et al. (2010) Stomata: key players in the earth system, past and present. Current Opinion in Plant Biology 13, 232-239

53. Berendse, F., and Scheffer, M. (2009) The angiosperm radiation revisited, an ecological explanation for Darwin's 'abominable mystery'. Ecology Letters 12, 865-872 
54. Bogaard, A., et al. (2013) Crop manuring and intensive land management by Europe's

first farmers. Proceedings of the National Academy of Sciences 110, 12589-12594

55. Dotterweich, M., and Schreg, R. (2019) Archaeonics - (Geo)archaeological studies in Anthropogenic Dark Earths (ADE) as an example for future-oriented studies of the past.

Quaternary International 502, 309-318

56. Denevan, W.M. (1996) A Bluff Model of Riverine Settlement in Prehistoric Amazonia. Annals of the Association of American Geographers 86, 654-681

57. Mithen, S. (2010) The domestication of water: water management in the ancient world and its prehistoric origins in the Jordan Valley. Philosophical Transactions of the Royal Society A: Mathematical, Physical and Engineering Sciences 368, 5249-5274

58. Sen, A.K. (1959) The Choice of Agricultural Techniques in Underdeveloped Countries. Economic Development and Cultural Change 7, 279-285

59. Marshall, F., et al. (2018) Ancient herders enriched and restructured African grasslands. Nature 561, 387-390

60. Brierley, C., et al. (2018) Pastoralism may have delayed the end of the green Sahara. Nature Communications 9, 4018

61. Cook, B.I., et al. (2009) Amplification of the North American "Dust Bowl" drought through human-induced land degradation. Proceedings of the National Academy of Science $106,4997-5001$

62. Hornbeck, R. (2012) The Enduring Impact of the American Dust Bowl: Short- and Long-Run Adjustments to Environmental Catastrophe. American Economic Review 102, $1477-1507$

63. Swenson, W., et al. (2000) Artificial ecosystem selection. Proceedings of the National Academy of Sciences of the USA 97, 9110-9114 
497

498

499

500

501

502

503

504

505

506

507

508

509

510

511

512

513

514

515

516

517

518

519

64. Blouin, M., et al. (2015) Levels and limits in artificial selection of communities.

Ecology Letters 18, 1040-1048

65. Williams, H.T.P., and Lenton, T.M. (2007) Artificial selection of simulated microbial ecosystems. Proceedings of the National Academy of Sciences 104, 8918-8923

66. Williams, H.T.P., and Lenton, T.M. (2008) Environmental regulation in a network of simulated microbial ecosystems. Proceedings of the National Academy of Sciences 105, 10432-10437

67. Jones, C.G., et al. (1994) Organisms as ecosystem engineers. Oikos 69, 373-384

68. Klinger, L.F. (1996) Coupling of Soils and Vegetation in Peatland Succession. Arctic and Alpine Research 28, 380-387

69. Aussenac, G. (2000) Interactions between forest stands and microclimate:

Ecophysiological aspects and consequences for silviculture. Ann. For. Sci. 57, 287-301

70. Schotanus, J., et al. (2020) Promoting self-facilitating feedback processes in coastal ecosystem engineers to increase restoration success: Testing engineering measures. Journal of Applied Ecology, in press

71. Wrangham, R. (2017) Control of Fire in the Paleolithic: Evaluating the Cooking Hypothesis. Current Anthropology 58, S303-S313

72. Midgley, J.J. (2013) Flammability is not selected for, it emerges. Australian Journal of Botany 61, 102-106

73. Stevens, N., et al. (2018) Transplant Experiments Point to Fire Regime as Limiting Savanna Tree Distribution. Frontiers in Ecology and Evolution 6, 137

74. Bond, W.J. (2019) Open ecosystems; ecology and evolution beyond the forest edge.

Oxford University Press 
520

521

522

523

524

525

526

527

528

529

530

531

532

533

534

535

536

537

538

539

540

541

542

75. Bliege Bird, R., et al. (2012) Aboriginal hunting buffers climate-driven fire-size

variability in Australia's spinifex grasslands. Proceedings of the National Academy of Sciences $109,10287-10292$

76. McWethy, D.B., et al. (2010) Rapid landscape transformation in South Island, New Zealand, following initial Polynesian settlement. Proceedings of the National Academy of Sciences 107, 21343-21348

77. Bogaard, A., et al. (2018) Farming, Inequality, and Urbanization: A Comparative Analysis of Late Prehistoric Northern Mesopotamia and Southwestern Germany. In Ten Thousand Years of Inequality: the Archaeology of Wealth Differences (Kohler, T.A., and Smith, M.E., eds), 201-229, University of Arizona Press

78. Kohler, T.A., et al. (2017) Greater post-Neolithic wealth disparities in Eurasia than in North America and Mesoamerica. Nature 551, 619

79. Bettencourt, L.M.A., et al. (2014) Professional diversity and the productivity of cities. Scientific Reports 4, 5393

80. Durkheim, E. (1997 [1893]) The Division of Labour in Society. Trans. W. D. Halls, intro. Lewis A. Coser. Free Press

81. Loreau, M. (2010) From populations to ecosystems: theoretical foundations for a new ecological synthesis (MPB-46). Princeton University Press

82. Wright, A.J., et al. (2017) The Overlooked Role of Facilitation in Biodiversity Experiments. Trends in Ecology \& Evolution 32, 383-390

83. Ashby, W.R. (1952) Design for a Brain. Chapman \& Hall

84. Borrelli, J.J., et al. (2015) Selection on stability across ecological scales. Trends in Ecology \& Evolution 30, 417-425 
85. Fowler, C.W., and MacMahon, J.A. (1982) Selective Extinction and Speciation: Their Influence on the Structure and Functioning of Communities and Ecosystems. The American Naturalist 119, 480-498

86. Post, W.M., and Pimm, S.L. (1983) Community Assembly and Food Web Stability. Mathematical Biosciences 64, 169-192

87. Hamilton, W.D., and May, R.M. (1977) Dispersal in stable habitats. Nature 269, 578581

88. Roopnarine, P.D., et al. (2019) Ecological persistence, incumbency and reorganization in the Karoo Basin during the Permian-Triassic transition. Earth-Science Reviews 189, 244-263

89. Bocinsky, R.K., et al. (2016) Exploration and exploitation in the macrohistory of the pre-Hispanic Pueblo Southwest. Science Advances 2, e1501532

90. Kohler, T.A., and Ellyson, L.J. (2018) In and Out of Chains?: The Changing Social Contract in the Pueblo Southwest, AD 600-1300. In Ten Thousand Years of Inequality (Kohler, T.A., and Smith, M.E., eds), 130-154, University of Arizona Press

91. Rosen, A.M., and Rivera-Collazo, I. (2012) Climate change, adaptive cycles, and the persistence of foraging economies during the late Pleistocene/Holocene transition in the Levant. Proceedings of the National Academy of Sciences 109, 3640-3645

92. Gronenborn, D., et al. (2017) Population dynamics, social resilience strategies, and Adaptive Cycles in early farming societies of SW Central Europe. Quaternary International $446,54-65$

93. Hobbes, T. (2010 [1651]) Leviathan: Or the Matter, Forme, and Power of a CommonWealth Ecclesiasticall and Civill, ed. by Ian Shapiro. Yale University Press 
566

567

568

569

570

571

572

573

574

575

576

577

578

579

580

581

582

583

584

585

586

587

588

589

94. Rappaport, R.A. (1968) Pigs for the Ancestors: Ritual in the Ecology of a New Guinea

People. Yale University Press

95. Rillig, M.C., and Antonovics, J. (2019) Microbial biospherics: The experimental study

of ecosystem function and evolution. Proceedings of the National Academy of Sciences 116, 11093-11098

96. Dunne, J.A., et al. (2008) Compilation and Network Analyses of Cambrian Food Webs. PLoS Biology 6, e102

97. Kohler, T.A. (2013) How the Pueblos Got Their Sprachbund. Journal of Archaeological Method and Theory 20, 212-234

98. Homer, J.B. (1982) Theories of the industrial revolution: A feedback perspective.

Dynamica 8, 30-35

99. Haff, P.K. (2013) Technology as a geological phenomenon: implications for human well-being. Geological Society, London, Special Publications 395, 301-309

100. Weinberger, V.P., et al. (2017) Innovation and the growth of human population. Philosophical Transactions of the Royal Society B: Biological Sciences 372, 20160415

101. Lenton, T.M., and Latour, B. (2018) Gaia 2.0. Science 361, 1066-1068

102. Fisher, R.A. (1919) XV.-The Correlation between Relatives on the Supposition of Mendelian Inheritance. Transactions of the Royal Society of Edinburgh 52, 399-433

103. Roopnarine, P.D., and Angielczyk, K.D. (2019) Chapter 13. The Stability of Ecological Communities as an Agent of Evolutionary Selection: Evidence from the Permian-Triassic Mass Extinction. In Evolutionary Theory: A Hierarchical Perspective (Eldredge, N., et al., eds), 307-333, University of Chicago Press

104. Bourrat, P. (2014) How to Read 'Heritability' in the Recipe Approach to Natural Selection. The British Journal for the Philosophy of Science 66, 883-903 
590 105. Lamba, S. (2016) The empirical evidence that does not support cultural group

591 selection models for the evolution of human cooperation. Behavioral and Brain Sciences 39,

592 e44

593 106. Powell, A., et al. (2009) Late Pleistocene Demography and the Appearance of

594 Modern Human Behavior. Science 324, 1298-1301

595 107. Rillig, M.C., et al. (2015) Interchange of entire communities: microbial community

596 coalescence. Trends in Ecology \& Evolution 30, 470-476 
598

599

600

601

602

603

604

605

606

607

608

609

610

611

612

613

614

615

616

617

618

619

\section{Box 1: Relationship to existing theory}

Parallels and distinctions between proposed mechanisms of 'survival of the systems' and replication-based natural selection (Table 1 ) centre on the nature of information transmission over time (usually called "inheritance") and the type of selection.

Information transmission: Particulate inheritance plays a key role in replication-based selection because it prevents variation in fitness being diluted at each generation (as would occur under blending inheritance) [102]. Feedback cycle properties arise from the combined relations of components - here often both biotic and abiotic - making information transmission more complex. Information regarding the response of a biotic variable (e.g. grass) to another biotic variable (e.g. herbivores), or an abiotic one (e.g. fire), can be encoded in a recognised [36] (e.g. genetic) inheritance system. But if such links in feedback cycles are "re-produced" by unrelated organisms performing the same function [18] (i.e. breaking parent-offspring inheritance), one must look harder for continuity of information, e.g. to a common gene complex encoding a particular response [34], or a reference text in the cultural case. In general, a complex interplay between such physical structures and their environmental context serves to interpret the structures and confer on them a functional role. Information regarding the response of an abiotic variable to a biotic one (or another abiotic one) is not encoded, yet it may be conserved e.g. because it is governed by thermodynamics. Thus at least some pertinent information transmission resides in the persistence of feedback cycle structures. Conceivably, variation in particulate heritability may be subject to selection based on its impact on system performance [103]. Niche construction theory (NCT) recognises persistent niche states as derived from genetic 

information within the biological entities that create them, but it does not treat whole

621 niche-population feedback loops as units of selection.

622 Types of selection: Natural selection in cases of overlapping generations combines elements

623 of replication-based and persistence-based selection, which can be partitioned using the

624 Price equation [104]. Hence purely persistence-based selection can be formalised this way.

625 Recursive application of the Price equation can distinguish multiple levels of selection,

626 showing that selection at one level becomes a source of variation at the level above [28].

627 Multi-level selection type '2' recognises distinct (irreducible or "emergent") properties at 628 the higher-level that are subject to selection [28]. However, it retains an emphasis on

629 discrete replication, whereas we focus on purely persistence-based selection at the higher-

630 level: Different systems comprised of different feedback cycles differ in their propensity to

631 spread. Shared physical boundary conditions on Earth constrain the spread of ecosystems

632 and social-ecological systems. Hence different systems with different feedback properties

633 interact ("compete") and some may out-persist others. 
634

635

636

637

638

639

640

641

642

643

644

645

646

647

648

649

650

651

652

653

654

655

656

\section{Box 2: Dispersal mechanisms}

Dispersal (horizontal transfer) of individuals, norms and innovations and resultant recombination of successful components coming from different 'parent' systems provides a potential source of variation in feedback cycles, which may then be subject to persistencebased selection.

Genetic dispersal. Dispersal of members of genetically-related populations of an ecosystem or social system, is usually naturally selected because dispersal, even to an equally populated habitat, reduces the likelihood of competing with relatives [87]. Under neutral dispersal, members of larger groups will tend to spread at the expense of members of smaller ones. Hence models show that systems with self-perpetuating feedbacks that enable them to support larger populations tend to spread their components at the expense of systems that lack such feedbacks $[38,66]$. Humans also sometimes undertake 'selective migration' [13], involving the use of knowledge and foresight on the part of the migrators who usually seek to move to wealthier, safer and more just societies.

Cultural dispersal. In social systems innovations that are not tied to genetics can be horizontally transferred. Imitation provides one mechanism for the spread of groupbeneficial norms and the recombination of different group-beneficial norms arising in different populations [12]. However, it relies on fairly faithful imitation, which has been questioned [105]. Selective (biased) imitation of the best-performing strategy - 'selective transmission' - can overwhelm the eroding effect of inaccurate imitation, if population density is sufficiently high [106]. In principle, cultural dispersal can enable social systems to evolve much faster than ecosystems. The spread of literacy, ever-better means of transportation, and ever-faster means of communication have plausibly increased the 
importance of cultural evolution based on 'borrowing' (recombination) relative to slower

658 group extinction mechanisms [12].

659 System dispersal. In microbial ecology system-level dispersal can occur through community 660 coalescence [107]. Members of microbial communities produce extracellular compounds 661 that bind the entire community together (e.g. in a microbial mat) and thus facilitate 662 coherent dispersal. Thus, whilst system components may be genetically unrelated there may 663 still be some 'heritability' of the whole. A social equivalent of system dispersal is when 664 cultural groups going to colonise new lands take a whole system of skills, domesticated 665 plants and animals, and their language with them. The European colonization of the New 666 World was undertaken by competing national entities, but the diseases, plants, and animals 667 introduced by any one of these entities enhanced the disruption of Native polities that 668 facilitated the success of all the colonisers. 
670

671

\section{Outstanding questions}

- How should persistence-based selection of feedback cycles be mathematically formalized and modelled? The sign and strength of feedback cycles can be quantified by 'gain' factors. Selective and non-selective effects can be partitioned - at multiple levels - using the Price equation, but it relies on counting objects, whereas feedback cycles are patterns of relations, not objects.

- What are the relative influences of system-level persistence-based selection and lower-level replication-based selection where both are occurring? Empirical test cases where the levels and types of selection are in conflict may be the most revealing, if not the most common.

- Can persistence-based selection generate increasing complexity? Learning through a series of trials over time is inherently slower than learning through trials over time and space (i.e. replication-based selection) but should still be able to accumulate adaptations.

- Can persistence-based selection explain apparent convergent evolution of ecosystems? Recognizably similar ecosystem structures - e.g. savannahs, coral reefs and forests - are found assembled out of different species on different continents. The feedbacks involved appear conserved, whereas the component species performing specific functions in the feedback loops appear to be substitutable.

- Can archaeological cultures be explained as persistence-enhancing systems? Their spatial extent is large, and they sometimes contain several ethnolinguistic groups, making explanations based on cultural group selection problematic.

- Can a system persistence perspective help guide ecosystem-scale conservation efforts? Some ecosystem configurations may be destined not to persist, as local-to- 
694

695

696

697

global change pressures can tip them into alternative states leading to irreversible species loss. Looking across ecosystems to identify variation in their persistenceenhancing properties could provide a novel way to target ecosystem-scale protection efforts. 
698

699

700

701

702

703

704

705

706

707

708

709

710

711

712

713

714

715

716

\section{Glossary}

Archaeological culture: a recurring assemblage of artefacts, architectural styles and combined subsistence, settlement, and organizational practices, from a specific time and place that represent the material culture of a particular past human society, e.g. "Anasazi" and/or "Puebloan", "Hopewell", or "Weeden Island".

Autocatalytic network: a network of entities (usually chemical), the creation of each of which can be catalysed by other members of the network, such that the whole network can catalyse its own production.

By-product: a consequence of a phenotype selected for other reasons, for example, environmental changes due to excreted metabolic waste products. By-products can subsequently become selected for, e.g., if they form the basis of a closed recycling loop.

Cultural evolution: change in cultural information over time - that is information capable of affecting individuals' behaviour that is socially transmitted from other members of their species.

Ecosystem evolution: change in organisation over time here argued due to persistencebased selection operating on variation in irreducible ecosystem-level properties.

Functional redundancy: many species performing the same metabolic function.

Inheritance systems: genetic, epigenetic, behavioural, and cultural means of faithfully transmitting information through time. 
Irreducible properties: properties that cannot be assigned to any of the components of a system in isolation because they depend on the relations between components - for example, the self-amplifying or self-damping properties of feedback cycles.

Landesque capital: capital goods which replace land (e.g. fertiliser, irrigation, pest control), increasing yield without replacing labour (as distinct from laboresque capital goods which replace labour, e.g. tractors).

Mechanical solidarity: social cohesion coming from homogeneity of individuals, their values, and beliefs - people feel connected through similar work, education, religious training, and lifestyle.

Microbial guild: a group of microbial species that perform the same metabolic biogeochemical transformation (a guild more generally is a group of species that exploit the same resource).

Multi-level selection: Selection operating simultaneously on multiple levels of biological organisation. In type ' 1 ' the higher-level properties subject to selection are simple aggregates of lower-level properties. In type ' 2 ' - pertinent here - irreducible higher-level properties are subject to selection.

Organic solidarity: social cohesion based on the interdependence between people that arises from complementary specialisation of work. For example, farmers make food that feeds factory workers that make tractors that help farmers make food.

Persistence-based selection: differential persistence of non-reproducing entities, which exhibit variation, results in increasing frequencies of persistence-promoting properties among survivors. 
739

740

741

742

743

744

745

746

747 individuals. persist.

Replication-based selection: heritable variation in phenotypic traits among members of a reproducing population results in increasing frequencies of descendant-producing properties amongst the descendant population.

Sequential selection: repetitions of a system over time alone enable it to acquire stabilising mechanisms because fragile systems are fleeting whereas stable configurations tend to

Stability-based sorting: differential persistence of interacting, non-reproducing systems, which exhibit variation in their steady states, with those exhibiting more stable steady states coming to dominate.

Sponge loop: the hypothesis that sponges on coral reefs absorb large quantities of dissolved organic carbon released by seaweeds and corals and return it to the reef as particles in the form of living and dead cells, or other cellular debris.

Technosphere: that part of the Earth system that is made or modified by humans.

Ultra-social: the ability to co-operate with huge numbers of genetically unrelated 
Table 1. Relating mechanisms of survival of the systems discussed herein to other forms of selection

\begin{tabular}{|c|c|c|c|c|c|c|}
\hline $\begin{array}{l}\text { Property subject } \\
\text { to selection }\end{array}$ & Example & Mechanism & $\begin{array}{l}\text { Selection } \\
\text { acts upon } \\
\text { entities } \\
\text { within an } \\
\text { interacting } \\
\text { population? }\end{array}$ & \begin{tabular}{|l|} 
Negative \\
selection \\
removes \\
pre-existing \\
properties?
\end{tabular} & $\begin{array}{l}\text { Interaction between } \\
\text { selection and variation } \\
\text { produces novel } \\
\text { adaptations at the level } \\
\text { under selection? }\end{array}$ & References \\
\hline \multirow{3}{*}{$\begin{array}{l}\text { Heritable } \\
\text { variation } \\
\text { causing } \\
\text { differential } \\
\text { survival and } \\
\text { reproduction }\end{array}$} & $\begin{array}{l}\text { Natural selection } \\
\text { of individuals }\end{array}$ & $\begin{array}{l}\text { Organism-level survival and/or } \\
\text { reproduction }\end{array}$ & Yes & Yes & Yes & \multirow[t]{3}{*}[28]{} \\
\hline & $\begin{array}{l}\text { Multi-level } \\
\text { selection 'type 1' }\end{array}$ & $\begin{array}{l}\text { Group fitness equates to total } \\
\text { fitness of constituent individuals }\end{array}$ & Yes & Yes & $\begin{array}{l}\text { No (but knock-on effect on } \\
\text { organism-level adaptation) }\end{array}$ & \\
\hline & $\begin{array}{l}\text { Multi-level } \\
\text { selection 'type 2' }\end{array}$ & $\begin{array}{l}\text { Group fitness irreducible to } \\
\text { individual-level properties }\end{array}$ & Yes & Yes & Yes & \\
\hline $\begin{array}{l}\text { Propensity for } \\
\text { non-reproducing } \\
\text { systems to spread } \\
\text { across space }\end{array}$ & $\begin{array}{l}\text { Feedbacks upon } \\
\text { relative spread } \\
\text { of distinct } \\
\text { systems }\end{array}$ & $\begin{array}{l}\text { Differential spread and/or } \\
\text { encroachment based on distinct } \\
\text { environmental boundary } \\
\text { conditions }\end{array}$ & Yes & Yes & $\begin{array}{l}\text { No? (but knock-on effect } \\
\text { on organism-level } \\
\text { adaptation) }\end{array}$ & $\begin{array}{l}\text { [8] This } \\
\text { study }\end{array}$ \\
\hline \multirow[t]{3}{*}{$\begin{array}{l}\text { Propensity for } \\
\text { non-reproducing } \\
\text { systems to persist } \\
\text { through time }\end{array}$} & $\begin{array}{l}\text { "It's-the-song- } \\
\text { not-the-singers" } \\
\text { (ITSNTS) }\end{array}$ & $\begin{array}{l}\text { Feedback cycles interact with } \\
\text { biota in a way that affects their } \\
\text { persistence \& "recruit" biological } \\
\text { species to perform steps }\end{array}$ & No & Yes & $\begin{array}{l}\text { No? (but co-evolutionary } \\
\text { adaptations in individual } \\
\text { genomes) }\end{array}$ & {$[18,19]$} \\
\hline & $\begin{array}{l}\text { Generalized } \\
\text { stability-based } \\
\text { sorting }\end{array}$ & $\begin{array}{l}\text { Properties promoting static } \\
\text { physical stability inherently } \\
\text { promote persistence }\end{array}$ & No & Yes & No & {$[22,84]$} \\
\hline & $\begin{array}{l}\text { Sequential } \\
\text { selection for } \\
\text { dynamic stability } \\
\text { (cybernetics, } \\
\text { biogeochemistry) }\end{array}$ & $\begin{array}{l}\text { Reconfigurations when the } \\
\text { system-state exceeds certain } \\
\text { bounds tend to remove unstable } \\
\text { configurations and promote } \\
\text { stable ones }\end{array}$ & No & Yes & $\begin{array}{l}\text { Yes, provided no re-set } \\
\text { permanently undermines } \\
\text { the process (e.g. runaway } \\
\text { climatic feedbacks) }\end{array}$ & $\begin{array}{l}{[21,83]} \\
\text { This study }\end{array}$ \\
\hline
\end{tabular}




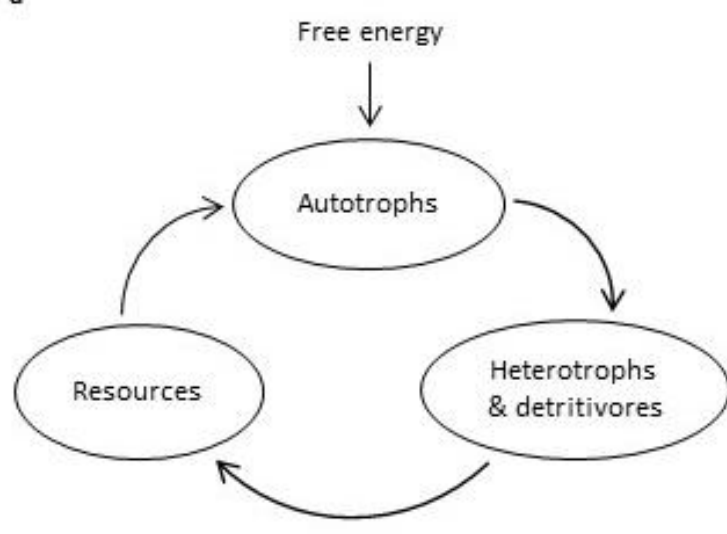

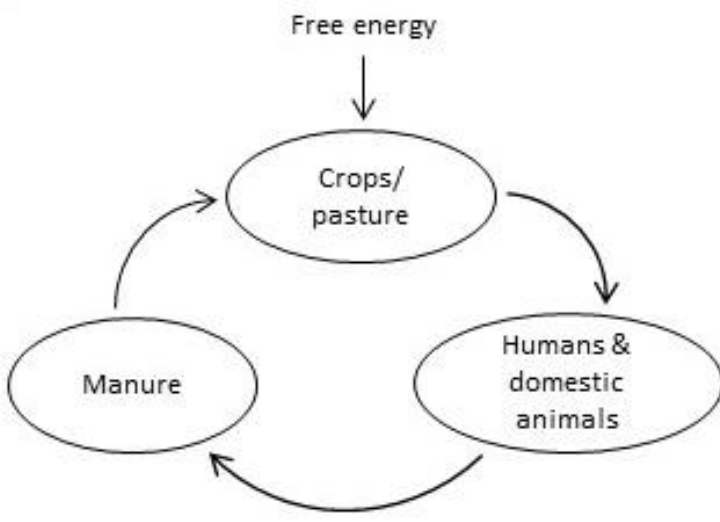

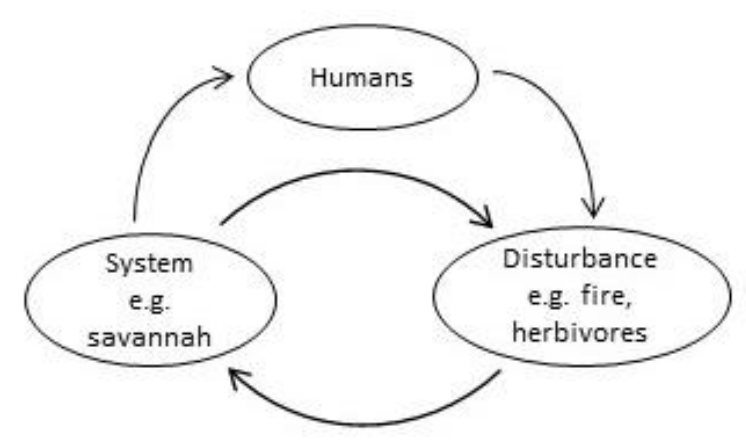

759

760

761

Fig. 1. Self-perpetuating (positive feedback) cycles. (a) Ecological resource recycling powered by free energy input. (b) Example of manuring in human agricultural systems. (c) Positive feedback between a system and disturbance factor(s): Example of savannah, fire and herbivores, further augmented by humans promoting fires and domestic animal grazing. 


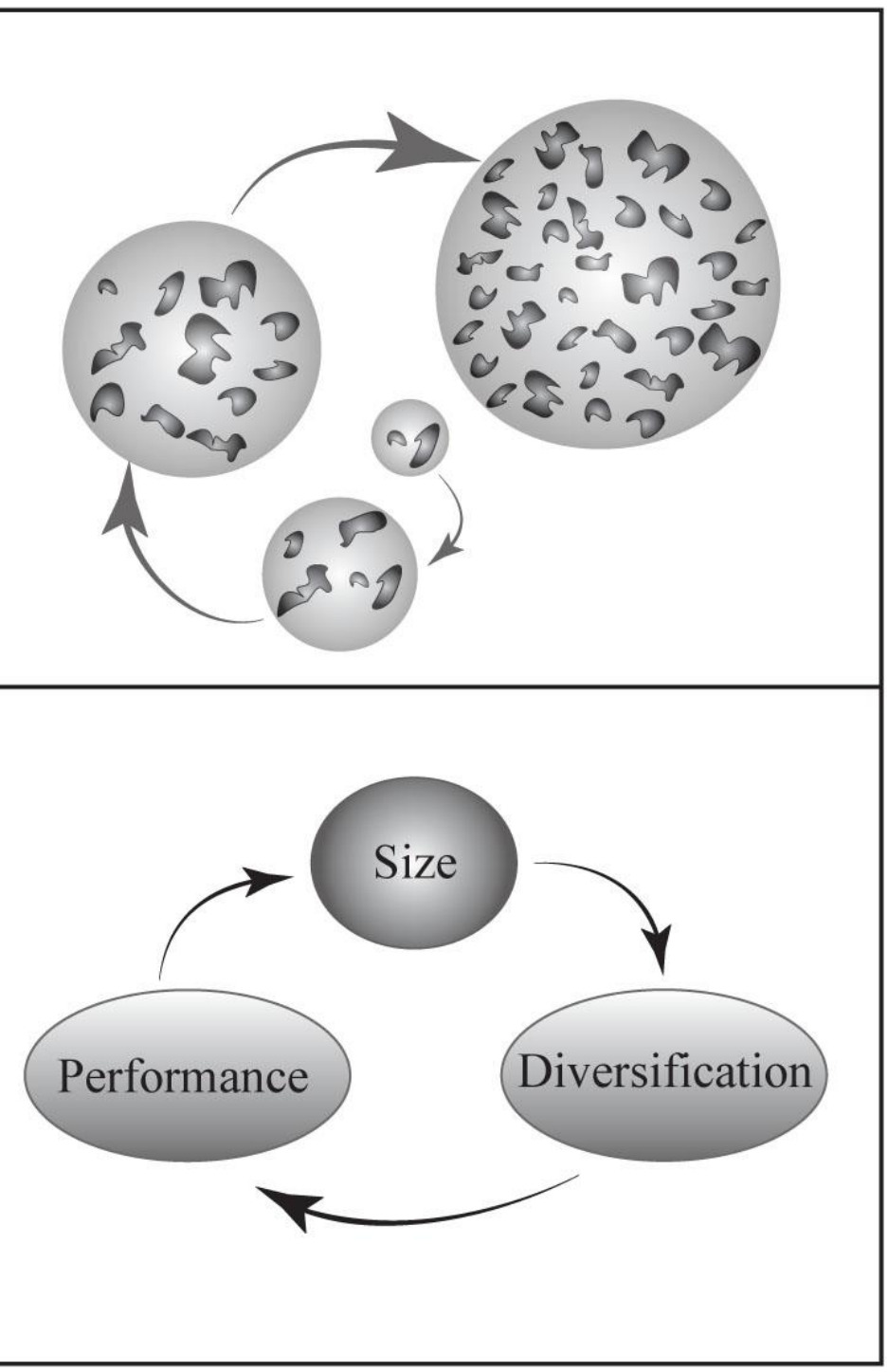

763

764 Fig. 2. How self-promoting cycles support diversification. Increased size allows

765 diversification which can improve performance thus promoting further growth of the 766 system. 